Budaya Organisasi di Sekolah, Oleh: Hamam

\title{
BUDAYA ORGANISASI DI SEKOLAH
}

\author{
$\operatorname{Hamam}^{*}$
}

\begin{abstract}
Abstrak
Pencapaian tujuan pendidikan dan peningkatan kinerja sekolah perlu dilakukan secara terus menerus dengan memperhatikan budaya organisasi di sekolah. Hal ini dimaksudkan agar tercipta iklim sekolah yang kondusif sehingga tercipta sekolah yang efektif.

Budaya organisasi mencakup umpan balik (feed back) dari masyarakat, profesi, hukum, kompetisi dan sebagainya. Jika dilihat dari proses, budaya organisasi mengacu kepada asumsi, nilai dan norma. Sedangkan dilihat dari out put, berhubungan dengan pengaruh budaya organisasi terhadap perilaku organisasi, teknologi, strategi, image, produk dan sebagainya
\end{abstract}

Kata Kunci: Budaya, Organisasi

\section{Pendahuluan}

Pemahaman tentang budaya organisasi sesungguhnya tidak lepas dari konsep dasar tentang budaya itu sendiri, yang merupakan salah satu terminologi yang banyak digunakan dalam bidang antropologi. Dewasa ini, dalam pandangan antropologi sendiri, konsep budaya ternyata telah mengalami pergeseran makna. Sebagaimana dinyatakan oleh C.A. Van Peursen bahwa dulu orang berpendapat budaya meliputi segala manifestasi dari kehidupan manusia yang berbudi luhur dan yang bersifat rohani, seperti : agama, kesenian, filsafat, ilmu pengetahuan, tata negara dan sebagainya. ${ }^{1}$ Tetapi pendapat tersebut sudah sejak lama disingkirkan. Dewasa ini budaya diartikan sebagai manifestasi kehidupan setiap orang dan setiap kelompok orang-orang. Kini budaya dipandang sebagai sesuatu yang lebih dinamis, bukan sesuatu yang kaku dan statis. Budaya tidak diartikan sebagai sebuah kata benda, kini lebih

\footnotetext{
* Dosen Institut Agama Islam Tribakti (IAIT) Kediri, DPK IAIN Sunan Ampel Surabaya.

1 Befring, E. 1997. The Enrichment Perspective. A Special Educational Approach to an Inclusive School. In Remedialand Special Educational no 3/97:182187. Journal International of Special Education, h. 6
}

Vol. 22 Nomor. 1 Januari 2011 
dimaknai sebagai sebuah kata kerja yang dihubungkan dengan kegiatan manusia.Dari sini timbul pertanyaan, apa sesungguhnya budaya itu ? Marvin Bower seperti disampaikain oleh Alan Cowling dan Philip James secara ringkas memberikan pengertian budaya sebagai "cara kita melakukan hal-hal di sini". 2

Menurut Vijay Santhe sebagaimana dikutip oleh Taliziduhu Ndraha budaya adalah : " The set of important assumption (often unstated) that members of community share in common". 3 Secara umum namun operasional, Edgar Schein dari MIT dalam tulisannya tentang Organizational Culture \& Leadership mendefinisikan budaya sebagai:

"A pattern of shared basic assumptions that the group learned as it solved its problems of external adaptation and internal integration, that has worked well enough to be considered valid and, therefore, to be taught to new members as the correct way you perceive, think, and feel in relation to those problems". 4

Dari Vijay Sathe dan Edgar Schein, kita temukan kata kunci dari pengertian budaya yaitu shared basic assumptions atau menganggap pasti terhadap sesuatu. Taliziduhu Ndraha mengemukakan bahwa asumsi meliputi beliefs (keyakinan) dan value (nilai). Beliefs merupakan asumsi dasar tentang dunia dan bagaimana dunia berjalan. Duverger sebagaimana dikutip oleh Idochi Anwar dan Yayat Hidayat Amir (2000) mengemukakan bahwa belief (keyakinan) merupakan state of mind (lukisan fikiran) yang terlepas dari ekspresi material yang diperoleh suatu komunitas. ${ }^{5}$

Value (nilai) merupakan suatu ukuran _ormative yang mempengaruhi manusia untuk melaksanakan tindakan yang dihayatinya. Menurut Vijay Sathe dalam Taliziduhu (1997) nilai

2 Alan Cowling \& Philip James. 1996 .The Essence of Personnel Management and Industrial Relations (terj. Xavier Quentin Pranata). Yogyakarta: ANDI. h. 10

${ }^{3}$ E. Befring, 1997. The Enrichment Perspective.. h. 7

4 Hay Group. 2003,. "Intervention: Managerial Style \& Organizational Climate Assessment”. (http:// hayresourcesdirect. haygroup.com/ Misc/style_climate_intervention.asp.) h. 25

5 Idochi Anwar dan Yayat Hidayat Amir,. 2000. Administrasi Pendidikan : Teori, Konsep \& Issu, Bandung : Program Pasca Sarjana UPI Bandung h. 18 
Budaya Organisasi di Sekolah, Oleh: Hamam

merupakan " basic assumption about what ideals are desirable or worth striving for." 6

Dalam penjelasan lain dikemukakan pula bahwa nilai mempunyai fungsi : (1) nilai sebagai standar; (2) nilai sebagai dasar penyelesaian konflik dan pembuatan keputusan; (3) nilai sebagai motivasi; (4) nilai sebagai dasar penyesuaian diri; dan (5) nilai sebagai dasar perwujudan diri. Hal senada dikemukakan oleh Rokeach yang dikutip oleh Danandjaya dalam Taliziduhu Ndraha bahwa : " a value system is learned organization rules to help one choose between alternatives, solve conflict, and make decision."

Dalam budaya organisasi ditandai adanya sharing atau berbagi nilai dan keyakinan yang sama dengan seluruh anggota organisasi. Misalnya berbagi nilai dan keyakinan yang sama melalui pakaian seragam. Namun menerima dan memakai seragam saja tidaklah cukup. Pemakaian seragam haruslah membawa rasa bangga, menjadi alat kontrol dan membentuk citra organisasi. Dengan demikian, nilai pakaian seragam tertanam menjadi basic. Menurut Sathe dalam Taliziduhu Ndraha bahwa shared basic assumptions meliputi : (1) shared things; (2) shared saying, (3) shared doing; dan (4) shared feelings. ${ }^{8}$

Edgar Schein (2002) menyebutkan bahwa basic assumption dihasilkan melalui : (1) evolve as solution to problem is repeated over and over again; (2) hypothesis becomes reality, dan (3) to learn something new requires resurrection, reexamination, frame breaking. ${ }^{9}$

Dengan memahami konsep dasar budaya secara umum di atas, selanjutnya kita akan berusaha memahami budaya dalam konteks organisasi atau biasa disebut budaya organisasi (organizational culture). Adapun pengertian organisasi di sini lebih diarahkan dalam pengertian organisasi formal. Dalam arti, kerja sama yang terjalin antar anggota memiliki unsur visi dan misi, sumber daya, dasar hukum struktur, dan anatomi yang jelas dalam rangka mencapai tujuan tertentu.

Sejak lebih dari seperempat abad yang lalu, kajian tentang budaya organisasi menjadi daya tarik tersendiri bagi kalangan ahli maupun praktisi manajemen, terutama dalam rangka memahami dan mempraktekkan perilaku organisasi.

\footnotetext{
${ }^{6}$ E. Befring, 1997 h. 10

${ }^{7}$ Ibid.

${ }^{8}$ Ibid.

${ }^{9}$ Hay Group. 2003,. "Intervention: Managerial Style, h. 34
}

Vol. 22 Nomor. 1 Januari 2011 
Selanjuynya Edgar Schein mengemukakan bahwa budaya organisasi dapat dibagi ke dalam dua dimensi yaitu :

Dimensi external environments; yang didalamnya terdapat lima hal esensial yaitu: (a) mission and strategy; (b) goals; (c) means to achieve goals; (d) measurement; dan (e) correction.

Dimensi internal integration yang di dalamnya terdapat enam aspek utama, yaitu : (a) common language; (b) group boundaries for inclusion and exclusion; (c) distributing power and status; (d) developing norms of intimacy, friendship, and love; (e) reward and punishment; dan (f) explaining and explainable : ideology and religion. ${ }^{10}$

Sementara itu, Fred Luthan (1995) mengetengahkan enam karakteristik penting dari budaya organisasi, yaitu : (1) obeserved behavioral regularities; yakni keberaturan cara bertindak dari para anggota yang tampak teramati. Ketika anggota organisasi berinteraksi dengan anggota lainnya, mereka mungkin menggunakan bahasa umum, istilah, atau ritual tertentu; (2) norms; yakni berbagai standar perilaku yang ada, termasuk di dalamnya tentang pedoman sejauh mana suatu pekerjaan harus dilakukan; (3) dominant values; yaitu adanya nilai-nilai inti yang dianut bersama oleh seluruh anggota organisasi, misalnya tentang kualitas produk yang tinggi, absensi yang rendah atau efisiensi yang tinggi; (4) philosophy; yakni adanya kebijakan-kebijakan yang berkenaan dengan keyakinan organisasi dalam memperlakukan pelanggan dan karyawan (5) rules; yaitu adanya pedoman yang ketat, dikaitkan dengan kemajuan organisasi (6) organization climate; merupakan perasaan keseluruhan (an overall "feeling") yang tergambarkan dan disampaikan melalui kondisi tata ruang, cara berinteraksi para anggota organisasi, dan cara anggota organisasi memperlakukan dirinya dan pelanggan atau orang lain ${ }^{11}$

Dari ketiga pendapat di atas, kita melihat adanya perbedaan pandangan tentang karakteristik budaya organisasi, terutama dilihat dari segi jumlah karakteristik budaya organisasi. Kendati demikian, ketiga pendapat tersebut sesungguhnya tidak menunjukkan perbedaan yang prinsipil.

${ }^{10}$ Hay Group. 2003,. "Intervention: Managerial Style h. 35

${ }^{11}$ Fred Luthan. 1995. Organizational Behavior. Singapore: McGraw-Hill,Inc h. 20 
Budaya Organisasi di Sekolah, Oleh: Hamam

Budaya organisasi dapat dipandang sebagai sebuah sistem. Mc Namara mengemukakan bahwa dilihat dari sisi input, budaya organisasi mencakup umpan balik (feed back) dari masyarakat, profesi, hukum, kompetisi dan sebagainya. Sedangkan dilihat dari proses, budaya organisasi mengacu kepada asumsi, nilai dan norma, misalnya nilai tentang : uang, waktu, manusia, fasilitas dan ruang. Sementara dilihat dari out put, berhubungan dengan pengaruh budaya organisasi terhadap perilaku organisasi, teknologi, strategi, image, produk dan sebagainya. ${ }^{12}$

Dilihat dari sisi kejelasan dan ketahanannya terhadap perubahan, John P. Kotter dan James L. Heskett (1998) memilah budaya organisasi menjadi dua tingkatan yang berbeda. ${ }^{13}$ Dikemukakannya, bahwa pada tingkatan yang lebih dalam dan kurang terlihat, nilai-nilai yang dianut bersama oleh orang dalam kelompok dan cenderung bertahan sepanjang waktu bahkan meskipun anggota kelompok sudah berubah. Pengertian ini mencakup tentang apa yang penting dalam kehidupan, dan dapat sangat bervariasi dalam perusahaan yang berbeda : dalam beberapa hal orang sangat mempedulikan uang, dalam hal lain orang sangat mempedulikan inovasi atau kesejahteraan karyawan. Pada tingkatan ini budaya sangat sukar berubah, sebagian karena anggota kelompok sering tidak sadar akan banyaknya nilai yang mengikat mereka bersama. Pada tingkat yang terlihat, budaya menggambarkan pola atau gaya perilaku suatu organisasi, sehingga karyawan-karyawan baru secara otomatis terdorong untuk mengikuti perilaku sejawatnya. Sebagai contoh, katakanlah bahwa orang dalam satu kelompok telah bertahun-tahun menjadi "pekerja keras", yang lainnya "sangat ramah terhadap orang asing dan lainnya lagi selalu mengenakan pakaian yang sangat konservatif. Budaya dalam pengertian ini, masih kaku untuk berubah, tetapi tidak sesulit pada tingkatan nilai-nilai dasar. Untuk lebih jelasnya lagi mengenai tingkatan budaya ini dapat dilihat dalam bagan 1 .

Nilai yang dianut bersama : Keyakinan dan tujuan penting yang dimiliki bersama oleh kebanyakan orang dalam kelompok yang cenderung membentuk perilaku kelompok, dan sering bertahan lama, bahkan walaupun sudah terjadi perubahan dalam anggota kelompok. Contoh: para manajer yang mempedulikan pelanggan; eksekutif yang suka dengan pertimbangan jangka panjang.

${ }^{12}$ Hay Group. 2003,. "Intervention: Managerial Style h. 38

13 John P. Kotter. \& James L. Heskett, 1998. Corporate Culture and Performance. (terj Benyamin Molan). Jakarta: PT Prehalindo h. 22

Vol. 22 Nomor. 1 Januari 2011 
Budaya Organisasi di Sekolah, Oleh: Hamam

Norma perilaku kelompok : cara bertindak yang sudah lazim atau sudah meresap yang ditemukan dalam satu kelompok dan bertahan karena anggota kelompok cenderung berperilaku dengan cara mengajarkan praktek-praktek (juga- nilai-nilai yang mereka anut bersama) kepada para anggota baru memberi imbalan kepada mereka yang menyesuaikan dirinya dan menghukum yang tidak. Contoh: para karyawan cepat menanggapi permintaan pelanggan; para menajer yang sering melibatkan karyawan tingkat bawah dalam pengambilan keputusan.

Pada bagian lain, John P. Kotter dan James L. Heskett (1998) memaparkan pula tentang tiga konsep budaya organisasi yaitu: (1) budaya yang kuat; (2) budaya yang secara strategis cocok; dan (3) budaya adaptif. $^{14}$

Organisasi yang memiliki budaya yang kuat ditandai dengan adanya kecenderungan hampir semua manajer menganut bersama seperangkat nilai dan metode menjalankan usaha organisasi. Karyawan baru mengadopsi nilai-nilai ini dengan sangat cepat. Seorang eksekutif baru bisa saja dikoreksi oleh bawahannya, selain juga oleh bossnya, jika dia melanggar norma-norma organisasi. Gaya dan nilai dari suatu budaya yang cenderung tidak banyak berubah dan akar-akarnya sudah mendalam, walaupun terjadi penggantian manajer. Dalam organisasi dengan budaya yang kuat, karyawan cenderung berbaris mengikuti penabuh genderang yang sama. Nilai-nilai dan perilaku yang dianut bersama membuat orang merasa nyaman dalam bekerja, rasa komitmen dan loyalitas membuat orang berusaha lebih keras lagi. Dalam budaya yang kuat memberikan struktur dan kontrol yang dibutuhkan, tanpa harus bersandar pada birokrasi formal yang mencekik yang dapat menekan tumbuhnya motivasi dan inovasi.

Budaya yang strategis cocok secara eksplisit menyatakan bahwa arah budaya harus menyelaraskan dan memotivasi anggota, jika ingin meningkatkan kinerja organisasi. Konsep utama yang digunakan di sini adalah "kecocokan". Jadi, sebuah budaya dianggap baik apabila cocok dengan konteksnya. Adapun yang dimaksud dengan konteks bisa berupa kondisi obyektif dari organisasinya atau strategi usahanya.

Budaya yang adaptif berangkat dari logika bahwa hanya budaya yang dapat membantu organisasi mengantisipasi dan beradaptasi dengan perubahan lingkungan, akan diasosiasikan dengan kinerja yang

\footnotetext{
${ }^{14}$ Ibid. h. 24
} 
superiror sepanjang waktu. Ralph Klimann menggambarkan budaya adaptif ini merupakan sebuah budaya dengan pendekatan yang bersifat siap menanggung resiko, percaya, dan proaktif terhadap kehidupan individu. Para anggota secara aktif mendukung usaha satu sama lain untuk mengidentifikasi semua masalah dan mengimplementasikan pemecahan yang dapat berfungsi. Ada suatu rasa percaya (confidence) yang dimiliki bersama. Para anggotanya percaya, tanpa rasa bimbang bahwa mereka dapat menata olah secara efektif masalah baru dan peluang apa saja yang akan mereka temui. Kegairahan yang menyebar luas, satu semangat untuk melakukan apa saja yang dia hadapi untuk mencapai keberhasilan organisasi. Para anggota ini reseptif terhadap perubahan dan inovasi. Rosabeth Kanter mengemukakan bahwa jenis budaya ini menghargai dan mendorong kewiraswastaan, yang dapat membantu sebuah organisasi beradaptasi dengan lingkungan yang berubah, dengan memungkinkannya mengidentifikasi dan mengeksploitasi peluang-peluang baru. Contoh perusahaan yang mengembangkan budaya adaptif ini adalah Digital Equipment Corporation dengan budaya yang mempromosikan inovasi, pengambilan resiko, pembahasan yang jujur, kewiraswastaan, dan kepemimpinan pada banyak tingkat dalam hierarki.

\section{Proses Pembentukan Budaya Organisasi}

Munculnya gagasan-gagasan atau jalan keluar yang kemudian tertanam dalam suatu budaya dalam organisasi bisa bermula dari mana pun, dari perorangan atau kelompok, dari tingkat bawah atau puncak. Sumber-sumber pembentuk budaya organisasi, diantaranya : (1) pendiri organisasi; (2) pemilik organisasi; (3) Sumber daya manusia asing; (4) luar organisasi; (4) orang yang berkepentingan dengan organisasi (stake holder); dan (6) masyarakat. Selanjutnya dikemukakan pula bahwa proses budaya dapat terjadi dengan cara: (1) kontak budaya; (2) benturan budaya; dan (3) penggalian budaya. Pembentukan budaya tidak dapat dilakukan dalam waktu yang sekejap, namun memerlukan waktu dan bahkan biaya yang tidak sedikit untuk dapat menerima nilainilai baru dalam organisasi.

Setelah mapan, budaya organisasi sering mengabadikan dirinya dalam sejumlah hal. Calon anggota kelompok mungkin akan disaring berdasarkan kesesuaian nilai dan perilakunya dengan budaya organisasi. Kepada anggota organisasi yang baru terpilih bisa diajarkan gaya kelompok secara eksplisit. Kisah-kisah atau legenda-legenda historis 
bisa diceritakan terus menerus untuk mengingatkan setiap orang tentang nilai-nilai kelompok dan apa yang dimaksudkan dengannya.

Dalam suatu organisasi sesungguhnya tidak ada budaya yang "baik" atau "buruk", yang ada hanyalah budaya yang "cocok" atau "tidak cocok". Jika dalam suatu organisasi memiliki budaya yang cocok, maka manajemennya lebih berfokus pada upaya pemeliharaan nilai-nilai- yang ada dan perubahan tidak perlu dilakukan. Namun jika terjadi kesalahan dalam memberikan asumsi dasar yang berdampak terhadap rendahnya kualitas kinerja, maka perubahan budaya mungkin diperlukan. Karena budaya ini telah berevolusi selama bertahun-tahun melalui sejumlah proses belajar yang telah berakar, maka mungkin saja sulit untuk diubah. Kebiasaan lama akan sulit dihilangkan. Walaupun demikian, Howard Schwartz dan Stanley Davis dalam bukunya Matching Corporate Culture and Business Strategy yang dikutip oleh Bambang Tri Cahyono mengemukakan empat alternatif pendekatan terhadap manajemen budaya organisasi, yaitu: (1) lupakan kultur; (2) kendalikan disekitarnya; (3) upayakan untuk mengubah unsur-unsur kultur agar cocok dengan strategi; dan (4) ubah strategi. Selanjutnya Bambang Tri Cahyono (1996) dengan mengutip pemikiran Alan Kennedy dalam bukunya Corporate Culture mengemukan bahwa terdapat lima alasan untuk membenarkan perubahan budaya secara besar-besaran : (1) Jika organisasi memiliki nilai-nilai yang kuat namun tidak cocok dengan lingkungan yang berubah; (2) Jika organisasi sangat bersaing dan bergerak dengan kecepatan kilat; (3) Jika organisasi berukuran sedang-sedang saja atau lebih buruk lagi; (4) Jika organisasi mulai memasuki peringkat yang sangat besar; dan (5) Jika organisasi kecil tetapi berkembang pesat. ${ }^{15}$

Selanjutnya Kennedy mengemukakan bahwa jika tidak ada satu pun alasan yang cocok dengan di atas, jangan lakukan perubahan. Analisisnya terhadap sepuluh kasus usaha mengubah budaya menunjukkan bahwa hal ini akan memakan biaya antara 5 sampai 10 persen dari yang telah dihabiskan untuk mengubah perilaku orang. Meskipun demikian mungkin hanya akan didapatkan setengah perbaikan dari yang diinginkan. Dia mengingatkan bahwa hal itu akan memakan biaya lebih banyak lagi. dalam bentuk waktu, usaha dan uang.

${ }^{15}$ Komariah, A. \& Cepi, T. 2005. Visionary Leadership: Menuju Sekolah Efektif, Jakarta : BumiAksara h. 35 
Budaya Organisasi di Sekolah, Oleh: Hamam

\section{Pengembangan Budaya Organisasi di Sekolah}

Dengan memahami konsep tentang budaya organisasi sebagaimana telah diutarakan di atas, selanjutnya di bawah ini akan diuraikan tentang pengembangan budaya organisasi dalam konteks persekolahan. Secara umum, penerapan konsep budaya organisasi di sekolah sebenarnya tidak jauh berbeda dengan penerapan konsep budaya organisasi lainnya. Kalaupun terdapat perbedaan mungkin hanya terletak pada jenis nilai dominan yang dikembangkannya dan karakateristik dari para pendukungnya. Berkenaan dengan pendukung budaya organisasi di sekolah Paul E. Heckman sebagaimana dikutip oleh Stephen Stolp (1994) mengemukakan bahwa "the commonly held beliefs of teachers, students, and principals."

Nilai-nilai yang dikembangkan di sekolah, tentunya tidak dapat dilepaskan dari keberadaan sekolah itu sendiri sebagai organisasi pendidikan, yang memiliki peran dan fungsi untuk berusaha mengembangkan, melestarikan dan mewariskan nilai-nilai budaya kepada para siswanya. Dalam hal ini, Larry Lashway (1996) menyebutkan bahwa "schools are moral institutions, designed to promote social norms,...".

Nilai-nilai yang mungkin dikembangkan di sekolah tentunya sangat beragam. Jika merujuk pada pemikiran Spranger sebagaimana disampaikan oleh Sumadi Suryabrata (1990), maka setidaknya terdapat enam jenis nilai yang seyogyanya dikembangkan di sekolah. Dalam tabel 1 berikut ini dikemukakan keenam jenis nilai dari Spranger beserta perilaku dasarnya.

Tabel 1. Jenis Nilai dan Perilaku Dasarnya menurut Spranger

\begin{tabular}{|r|l|l|}
\hline No & Nilai & \multicolumn{1}{|c|}{ Perilaku Dasar } \\
\hline 1 & Ilmu Pengetahuan & Berfikir \\
\hline 2 & Ekonomi & Bekerja \\
\hline 3 & Kesenian & Menikmati keindahan \\
\hline 4 & Keagamaan & Memuja \\
\hline 5 & Kemasyarakatan & Berbakti/berkorban \\
\hline 6 & Politik/kenegaraan & Berkuasa/memerintah \\
\hline
\end{tabular}

Sumber : Modifikasi dari Sumadi Suryabrata. 1990. Psikologi Kepribadian. Jakarta: Rajawali.

Dengan merujuk pada pemikiran Fred Luthan, dan Edgar Schein, di bawah ini akan diuraikan tentang karakteristik budaya organisasi di 
Budaya Organisasi di Sekolah, Oleh: Hamam

sekolah, yaitu tentang (1) obeserved behavioral regularities; (2) norms; (3) dominant value. (4) philosophy; (5) rules dan (6) organization climate. $^{16}$

1. Obeserved behavioral regularities budaya organisasi di sekolah ditandai dengan adanya keberaturan cara bertindak dari seluruh anggota sekolah yang dapat diamati. Keberaturan berperilaku ini dapat berbentuk acara-acara ritual tertentu, bahasa umum yang digunakan atau simbol-simbol tertentu, yang mencerminkan nilainilai yang dianut oleh anggota sekolah.

2. Norms; budaya organisasi di sekolah ditandai pula oleh adanya norma-norma yang berisi tentang standar perilaku dari anggota sekolah, baik bagi siswa maupun guru. Standar perilaku ini bisa berdasarkan pada kebijakan intern sekolah itu sendiri maupun pada kebijakan pemerintah daerah dan pemerintah pusat. Standar perilaku siswa terutama berhubungan dengan pencapaian hasil belajar siswa, yang akan menentukan apakah seorang siswa dapat dinyatakan lulus/naik kelas atau tidak. Standar perilaku siswa tidak hanya berkenaan dengan aspek kognitif atau akademik semata namun menyangkut seluruh aspek kepribadian. Jika kita berpegang pada Kurikulum Berbasis Kompetensi, secara umum standar perilaku yang diharapkan dari tamatan Sekolah Menengah Atas, diantaranya mencakup : (1) Memiliki keyakinan dan ketaqwaan sesuai dengan ajaran agama yang dianutnya; (2)Memiliki nilai dasar humaniora untuk menerapkan kebersamaan dalam kehidupan; (3) Menguasai pengetahuan dan keterampilan akademik serta beretos belajar untuk melanjutkan pendidikan; (4) Mengalihgunakan kemampuan akademik dan keterampilan hidup dimasyarakat local dan global; (5) Berekspresi dan menghargai seni; (6) Menjaga kebersihan, kesehatan dan kebugaran jasmani; (7) Berpartisipasi dan berwawasan kebangsaan dalam kehidupan bermasyarakat, berbangsa, dan bernegara secara demokratis. (Depdiknas, 2002). Sedangkan berkenaan dengan standar perilaku guru, tentunya erat kaitannya dengan standar kompetensi yang harus dimiliki guru, yang akan menopang terhadap kinerjanya. Dalam perspektif kebijakan pendidikan nasional, pemerintah telah merumuskan empat jenis kompetensi guru sebagaimana tercantum dalam Penjelasan Peraturan Pemerintah No 14 Tahun 2005 tentang Standar Nasional Pendidikan,

${ }^{16}$ Fred Luthan. 1995. Organizational Behavior. h. 31 
yaitu : (1) Kompetensi pedagogik yaitu merupakan kemampuan dalam pengelolaan peserta didik yang meliputi: (a) pemahaman wawasan atau landasan kependidikan; (b) pemahaman terhadap peserta didik; (c) pengembangan kurikulum/ silabus; (d) perancangan pembelajaran; (e) pelaksanaan pembelajaran yang mendidik dan dialogis; (f) evaluasi hasil belajar; dan (g) pengembangan peserta didik untuk mengaktualisasikan berbagai potensi yang dimilikinya; (2) Kompetensi kepribadian yaitu merupakan kemampuan kepribadian yang: (a) mantap; (b) stabil; (c) dewasa; (d) arif dan bijaksana; (e) berwibawa; (f) berakhlak mulia; (g) menjadi teladan bagi peserta didik dan masyarakat; (h) mengevaluasi kinerja sendiri; dan (i) mengembangkan diri secara berkelanjutan; (3) Kompetensi sosial yaitu merupakan kemampuan pendidik sebagai bagian dari masyarakat untuk : (a) berkomunikasi lisan dan tulisan; (b) menggunakan teknologi komunikasi dan informasi secara fungsional; (c) bergaul secara efektif dengan peserta didik, sesama pendidik, tenaga kependidikan, orangtua/wali peserta didik; dan (d) bergaul secara santun dengan masyarakat sekitar; dan (4) Kompetensi profesional merupakan kemampuan penguasaan materi pembelajaran secara luas dan mendalam yang meliputi: (a) konsep, struktur, dan metoda keilmuan/teknologi/seni yang menaungi/koheren dengan materi ajar; (b) materi ajar yang ada dalam kurikulum sekolah; (c) hubungan konsep antar mata pelajaran terkait; (d) penerapan konsepkonsep keilmuan dalam kehidupan sehari-hari; dan (e) kompetisi secara profesional dalam konteks global dengan tetap melestarikan nilai dan budaya nasional.

3. Dominant values; jika dihubungkan dengan tantangan pendidikan Indonesia dewasa ini yaitu tentang pencapaian mutu pendidikan, maka budaya organisasi di sekolah seyogyanya diletakkan dalam kerangka pencapaian mutu pendidikan di sekolah. Nilai dan keyakinan akan pencapaian mutu pendidikan di sekolah hendaknya menjadi hal yang utama bagi seluruh warga sekolah. Adapun tentang makna dari mutu pendidikan itu sendiri, Jiyono sebagaimana disampaikan oleh Sudarwan Danim (2002) mengartikannya sebagai gambaran keberhasilan pendidikan dalam mengubah tingkah laku anak didik yang dikaitkan dengan tujuan pendidikan. Sementara itu, dalam konteks Manajemen Peningkatan Mutu Berbasis Sekolah (Depdiknas, 2001), mutu pendidikan meliputi aspek input, proses dan output pendidikan. Pada aspek input, mutu pendidikan 
ditunjukkan melalui tingkat kesiapan dan ketersediaan sumber daya, perangkat lunak, dan harapan-harapan. Makin tinggi tingkat kesiapan input, makin tinggi pula mutu input tersebut. Sedangkan pada aspek proses, mutu pendidikan ditunjukkan melalui pengkoordinasian dan penyerasian serta pemanduan input sekolah dilakukan secara harmonis, sehingga mampu menciptakan situasi pembelajaran yang menyenangkan (enjoyable learning), mampu mendorong motivasi dan minat belajar, dan benar-benar mampu memberdayakan peserta didik. Sementara, dari aspek out put, mutu pendidikan dapat dilihat dari prestasi sekolah, khususnya prestasi siswa, baik dalam bidang akademik maupun non akademik. Berbicara tentang upaya menumbuh-kembangkan budaya mutu di sekolah akan mengingatkan kita kepada suatu konsep manajemen dengan apa yang dikenal dengan istilah Total Quality Management (TQM), yang merupakan suatu pendekatan dalam menjalankan suatu unit usaha untuk mengoptimalkan daya saing organisasi melalui prakarsa perbaikan terus menerus atas produk, jasa, manusia, proses kerja, dan lingkungannya. Berkaitan dengan bagaimana TQM dijalankan, Gotsch dan Davis sebagaimana dikutip oleh Sudarwan Danim (2002) mengemukakan bahwa aplikasi TQM didasarkan atas kaidah-kaidah : (1) Fokus pada pelanggan; (2) obsesi terhadap kualitas; (3) pendekatan ilmiah; (4) komitmen jangka panjang; (5) kerjasama tim; (6) perbaikan kinerja sistem secara berkelanjutan; (7) diklat dan pengembangan; (8) kebebasan terkendali; kesatuan tujuan; dan (10) keterlibatan dan pemberdayaan karyawan secara optimal. Dengan mengutip pemikiran Scheuing dan Christopher, dikemukakan pula empat prinsip utama dalam mengaplikasikan TQM, yaitu: (1) kepuasan pelanggan, (2) respek terhadap setiap orang; (3) pengelolaan berdasarkan fakta, dan (4) perbaikan secara terus menerus.(Sudarwan Danim, 2002). Selanjutnya, dalam konteks Manajemen Peningkatan Mutu Berbasis Sekolah, Depdiknas (2001) telah memerinci tentang elemen-elemen yang terkandung dalam budaya mutu di sekolah, yakni : (a) informasi kualitas harus digunakan untuk perbaikan; bukan untuk mengadili/ mengontrol orang; (b) kewenangan harus sebatas tanggung jawab; (c) hasil harus diikuti penghargaan (reward) atau sanksi (punishment); (d) kolaborasi dan sinergi, bukan kompetisi, harus merupakan basis kerja sama; (e) warga sekolah merasa aman terhadap pekerjaannya; (f) atmosfir keadilan (fairness) harus ditanamkan; (g) imbal jasa harus 
Budaya Organisasi di Sekolah, Oleh: Hamam

sepadan dengan nilai pekerjaannya; dan (h) warga sekolah merasa memiliki sekolah. Di lain pihak, Jann E. Freed et. al. (1997) dalam tulisannya tentang A Culture for Academic Excellence: Implementing the Quality Principles in Higher Education. dalam ERIC Digest memaparkan tentang upaya membangun budaya keunggulan akademik pada pendidikan tinggi, dengan menggunakan prinsipprinsip Total Quality Management, yang mencakup : (1) vision, mission, and outcomes driven; (2) systems dependent; (3) leadership: creating a quality culture; (4) systematic individual development; (4) decisions based on fact; (5) delegation of decision making; (6) collaboration; (7) planning for change; dan (8) leadership: supporting a quality culture. Dikemukakan pula bahwa "when the quality principles are implemented holistically, a culture for academic excellence is created. Dari pemikiran Jan E.Freed et. al. di atas, kita dapat menarik benang merah bahwa untuk dapat membangun budaya keunggulan akademik atau budaya mutu pendidikan betapa pentingnya kita untuk dapat mengimplementasikan prinsip-prinsip Total Quality Management, dan menjadikannya sebagai nilai dan keyakinan bersama dari setiap anggota sekolah.

4. Philosophy; budaya organisasi ditandai dengan adanya keyakinan dari seluruh anggota organisasi dalam memandang tentang sesuatu secara hakiki, misalnya tentang waktu, manusia, dan sebagainya, yang dijadikan sebagai kebijakan organisasi. Jika kita mengadopsi filosofi dalam dunia bisnis yang memang telah terbukti memberikan keunggulan pada perusahaan, di mana filosofi ini diletakkan pada upaya memberikan kepuasan kepada para pelanggan, maka sekolah pun seyogyanya memiliki keyakinan akan pentingnya upaya untuk memberikan kepuasan kepada pelanggan. Dalam konteks Manajemen Peningkatan Mutu Berbasis Sekolah, Depdiknas (2001) mengemukakan bahwa : "pelanggan, terutama siswa harus merupakan fokus dari semua kegiatan di sekolah. Artinya, semua in put - proses yang dikerahkan di sekolah tertuju utamanya untuk meningkatkan mutu dan kepuasan peserta didik . Konsekuensi logis dari ini semua adalah bahwa penyiapan in put, proses belajar mengajar harus benar-benar mewujudkan sosok utuh mutu dan kepuasan yang diharapkan siswa."

5. Rules; budaya organisasi ditandai dengan adanya ketentuan dan aturan main yang mengikat seluruh anggota organisasi. Setiap

Vol. 22 Nomor. 1 Januari 2011 
Budaya Organisasi di Sekolah, Oleh: Hamam

sekolah memiliki ketentuan dan aturan main tertentu, baik yang bersumber dari kebijakan sekolah setempat, maupun dari pemerintah, yang mengikat seluruh warga sekolah dalam berperilaku dan bertindak dalam organisasi. Aturan umum di sekolah ini dikemas dalam bentuk tata- tertib sekolah (school discipline), di dalamnya berisikan tentang apa yang boleh dan tidak boleh dilakukan oleh warga sekolah, sekaligus dilengkapi pula dengan ketentuan sanksi, jika melakukan pelanggaran. Joan Gaustad (1992) dalam tulisannya tentang School Discipline yang dipublikasikan dalam ERIC Digest 78 mengatakan bahwa : School discipline has two main goals: (1) ensure the safety of staff and students, and (2) create an environment conducive to learning.

6. Organization climate; budaya organisasi ditandai dengan adanya iklim organisasi. Hay Resources Direct (2003) mengemukakan bahwa "oorganizational climate is the perception of how it feels to work in a particular environment. It is the "atmosphere of the workplace" and people's perceptions of "the way we do things here

\section{Arti Penting Membangun Budaya Organisasi di Sekolah}

Pentingnya membangun budaya organisasi di sekolah terutama berkenaan dengan upaya pencapaian tujuan pendidikan sekolah dan peningkatan kinerja sekolah. Sebagaimana disampaikan oleh Stephen Stolp tentang School Culture yang dipublikasikan dalam ERIC Digest, dari beberapa hasil studi menunjukkan bahwa budaya organisasi di sekolah berkorelasi dengan peningkatan motivasi dan prestasi belajar siswa serta kepuasan kerja dan produktivitas guru ${ }^{17}$.

Begitu juga, studi yang dilakukan Leslie J. Fyans, Jr. dan Martin L. Maehr tentang pengaruh dari lima dimensi budaya organisasi di sekolah yaitu: tantangan akademik, prestasi komparatif, penghargaan terhadap prestasi, komunitas sekolah, dan persepsi tentang tujuan sekolah menunjukkan survey terhadap 16310 siswa tingkat empat, enam, delapan dan sepuluh dari 820 sekolah umum di Illinois, mereka lebih termotivasi dalam belajarnya dengan melalui budaya organisasi di sekolah yang kuat. Sementara itu, studi yang dilakukan, Jerry L. Thacker and William D. McInerney terhadap skor tes siswa sekolah dasar menunjukkan adanya pengaruh budaya organisasi di sekolah terhadap prestasi siswa. Studi yang dilakukannya memfokuskan tentang

${ }^{17}$ Hay Group. 2003,. "Intervention: Managerial Style h. 24 
Budaya Organisasi di Sekolah, Oleh: Hamam

new mission statement, goals based on outcomes for students, curriculum alignment corresponding with those goals, staff development, and building level decision-making. Budaya organisasi di sekolah juga memiliki korelasi dengan sikap guru dalam bekerja. Studi yang dilakukan Yin Cheong Cheng membuktikan bahwa "stronger school cultures had better motivated teachers. In an environment with strong organizational ideology, shared participation, charismatic leadership, and intimacy, teachers experienced higher job satisfaction and increased productivity". 18

Upaya untuk mengembangkan budaya organisasi di sekolah terutama berkenaan tugas kepala sekolah selaku leader dan manajer di sekolah. Dalam hal ini, kepala sekolah hendaknya mampu melihat lingkungan sekolahnya secara holistik, sehingga diperoleh kerangka kerja yang lebih luas guna memahami masalah-masalah yang sulit dan hubungan-hubungan yang kompleks di sekolahnya. Melalui pendalaman pemahamannya tentang budaya organisasi di sekolah, maka ia akan lebih baik lagi dalam memberikan penajaman tentang nilai, keyakinan dan sikap yang penting guna meningkatkan stabilitas dan pemeliharaan lingkungan belajarnya.

\section{Daftar Rujukan}

Alan Cowling \& Philip James. 1996 .The Essence of Personnel Management and Industrial Relations (terj. Xavier Quentin Pranata). Yogyakarta: ANDI.

American Association of School Administration, 1995, Staff Relations in School Administration Washington DC : American Association of School Administration

Brookver, W.B. \& Lezotte, L. (1982). Creating effective schools, Holmes Beach, FL:Learning Publication

Blunberg, A \& Greenfield, W. 1980. The Effective Principal : Perspecturs On School Leadersip, Boston: Allyn \& Bacon, Inc.

Bruce J. and Beverly S. "Improving In-Service Training: The Messages Of Research" Educational Leadership, 37 (February 1980), 37985

Befring, E. 1997. The Enrichment Perspective. A Special Educational Approach to an Inclusive School. In Remedialand Special

\footnotetext{
${ }^{18}$ Ibid.
}

Vol. 22 Nomor. 1 Januari 2011 
Budaya Organisasi di Sekolah, Oleh: Hamam

Educational no 3/97:182-187. Journal International of Special Education

CarterMcNamara. "Organizational Culture" The Management Assistance Program for

Nonprofits.(http://www.mapnp.org/library/orgthry/culturel culture. $\mathrm{htm})$

Depdiknas. 2001. Manajemen Peningkatan Mutu Berbasis Sekolah; Buku 1 Konsep dan Pelaksanaan. Jakarta : Direktorat SLTP Dirjen Dikdasmen,

Fred Luthan. 1995. Organizational Behavior. Singapore: McGrawHill,Inc.

Gregg, Russel T. 1957. "The Administration Process", in Roald

F.Campbell and R.T.Gregg, Eds., Administrative Behavior in Education. New York: Harper \& Row

Gorton, R.A., 1977, School Base Leadership: Challenges and Opportunities. USA : WCB.

Hay Group. 2003,. "Intervention: Managerial Style \& Organizational Climate Assessment”. (http:// hayresourcesdirect. haygroup.com/ Misc/style_climate_intervention.asp.)

Idochi Anwar dan Yayat Hidayat Amir,. 2000. Administrasi Pendidikan : Teori, Konsep \& Issu, Bandung : Program Pasca Sarjana UPI Bandung

Jann E. Freed. et.al. "A Culture for Academic Excellence: Implementing the Quality Principles in Higher Education". (http://www.ed.gov/databases/ERICDigests/ed406962.html).

Joan "Gaustad. "School Discipline" (http://eric.uoregon.edu/publications/ digests/digest078.html). ERIC Digest 78. December 1992

John P. Kotter. \& James L. Heskett, 1998. Corporate Culture and Performance. (terj Benyamin Molan). Jakarta: PT Prehalindo.

Joys, B., Weil, M. 1992, Model of Teaching, First Edition, Boston:

Allyn and Bacon

Komariah, A. \& Cepi, T. 2005. Visionary Leadership: Menuju Sekolah Efektif, Jakarta : BumiAksara

Owens, R.G. 1995. Organizational Behavior in Education. Boston: Allyn \& Bacon 